\section{Improving Membrane Staining of Cultured Cells Using Ferrocyanide as a Post-Fixative}

\author{
Stéphane Nizet \\ nizets2@yahoo.com
}

Lack of contrast is a common problem encountered when doing TEM of cultured cells, especially of membranes. Using ferrocyanide as a post-fixative can greatly improve membrane fixation and staining. This protocol has been used to study Caco-2 cells grown on PET membranes (the "Caco model"). Caco-2 is a colon cancer cell line that differentiates upon reaching confluency. This allows permeability studies on a cell model, which is reasonably similar to the human intestine.

Basically, the protocol is classical, the only peculiarity consisting in including ferrocyanide in post-fixation. I describe how I prepare and embed the membrane in order to obtain transverse sections of a cell monolayer because I find this is the only way to obtain regular sections with the cells sticking to the membrane (otherwise the ultrathin section splits between the cell and membrane).

1) Pipette the culture medium out and replace with warm Karnovsky fixative $\left(37^{\circ} \mathrm{C}\right)$ in $0.1 \mathrm{M}$ cacodylate buffer.

2) After 10 minutes fixation at room temperature, the membranes are cut out and transferred to Petri dishes containing cold Karnovsky $\left(4^{\circ} \mathrm{C}\right)$. As the membrane may float, it is important to have the side with the cells down in the fixative.

Continue fixation 4 hours to overnight at $4^{\circ} \mathrm{C}$.

Rinse fixative 3 times with the same cacodylate buffer at $4^{\circ} \mathrm{C}$ Rinse once with water at $4^{\circ} \mathrm{C}$

3) Cut the membrane in pieces and transfer on ice in minifuge tubes.*

4) Incubate the membrane for $1 \mathrm{~h}$. in Osmium and ferrocyanide (under the hood!) on ice:

$4 \mathrm{~mL} 1 \% \mathrm{OsO} 4$ in water $+0.03 \mathrm{~g} \mathrm{KFeCN}(329.26 \mathrm{~g} / \mathrm{mol})$. This ferrocyanide is also called "prussian red".

5) Wash 3 times with water at $4^{\circ} \mathrm{C}$

Dehydration in $50 \%, 70 \%, 95 \%$ Ethanol at $4^{\circ} \mathrm{C}$, each for 5 minutes

$3 \times 5$ minutes in abs. ethanol at $4^{\circ} \mathrm{C}$

5 minutes in a 1:1 mix of Ethanol and propylenoxide (R.T.)

5 minutes in propylenoxide

30 minutes in a 2:1 mix of propylenoxide and Epon

30 minutes in a 1:1 mix of propylenoxide and Epon

1 hour in a 1:2 mix of propylenoxide and Epon

1 hour in pure Epon

Replace with fresh Epon and leave overnight

Replace with fresh Epon and polymerize.

Personally, I use the traditional molds. In this case, it is necessary to open the oven every hour and verify that the membrane did not fall flat on the bottom of the mold. It takes 3-4 hours before the Epon becomes dense enough and the membrane stays vertical in the mold.

Cutting ultrathin sections is not easy, because it is important to keep the cell layer on the membrane (the cells tend to separate from the membrane) and because of the difference in hardness between the Epon and the PET membrane. The best way I have found is to cut a very large but very thin pyramid:

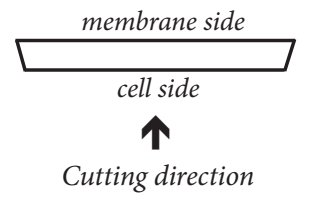

The small side of the pyramid should face the cells and the largest one should face the membrane. When cutting, the narrow end of the pyramid has to hit the knife first. This way there is no gap between the cells and the membrane. However, due to the difference in hardness of the cells and of the PET membrane, there are often differences in thickness in the sections, especially near the membrane.

It has also to be noted that serial sectioning is extremely difficult since, due to differences in thickness, it happens most often that each second section is not good. I was not able to cut sections thinner than $70 \mathrm{~nm}$. Perhaps it is possible to cut thinner sections using harder resin, but I have not tried this.

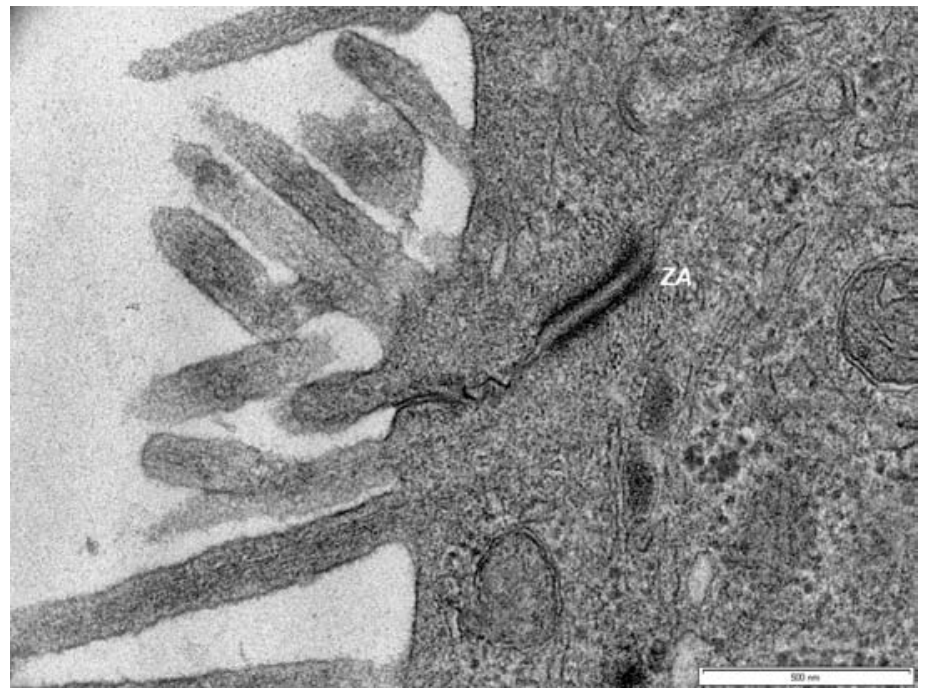

Caco-2 cell showing cell junctions including a zona adherens (ZA) and internal membranes, well preserved and contrasted after using $\mathrm{OsO}_{4}{ }^{-}$ $\mathrm{KFeCN}$ post-fixation.

The contrast and membrane preservation that can be obtained with this method is shown in the figure.

* The correct way to cut small pieces of membrane without detaching or destroying the cells is the following:

- Place the membrane on the upper side of a glass jar cover (it must be wet with cold water at all times)

- Using a new and clean razor blade in one hand and a spread forceps in the other hand, hold down the membrane with the open forceps (both ends must hold the membrane) while cutting 1 or 2 slices $2-3 \mathrm{~mm}$ wide with the razor blade.

- Isolate the stripes of membrane and cut smaller pieces (approx. $5-7 \mathrm{~mm}$ long) with a curved scalpel using a rotary movement.

- The small pieces of membrane are then transferred and treated in minifuge tubes. 


\section{Side-By-Side Comparison? Difficult When Our Coaters Stand Alone.}

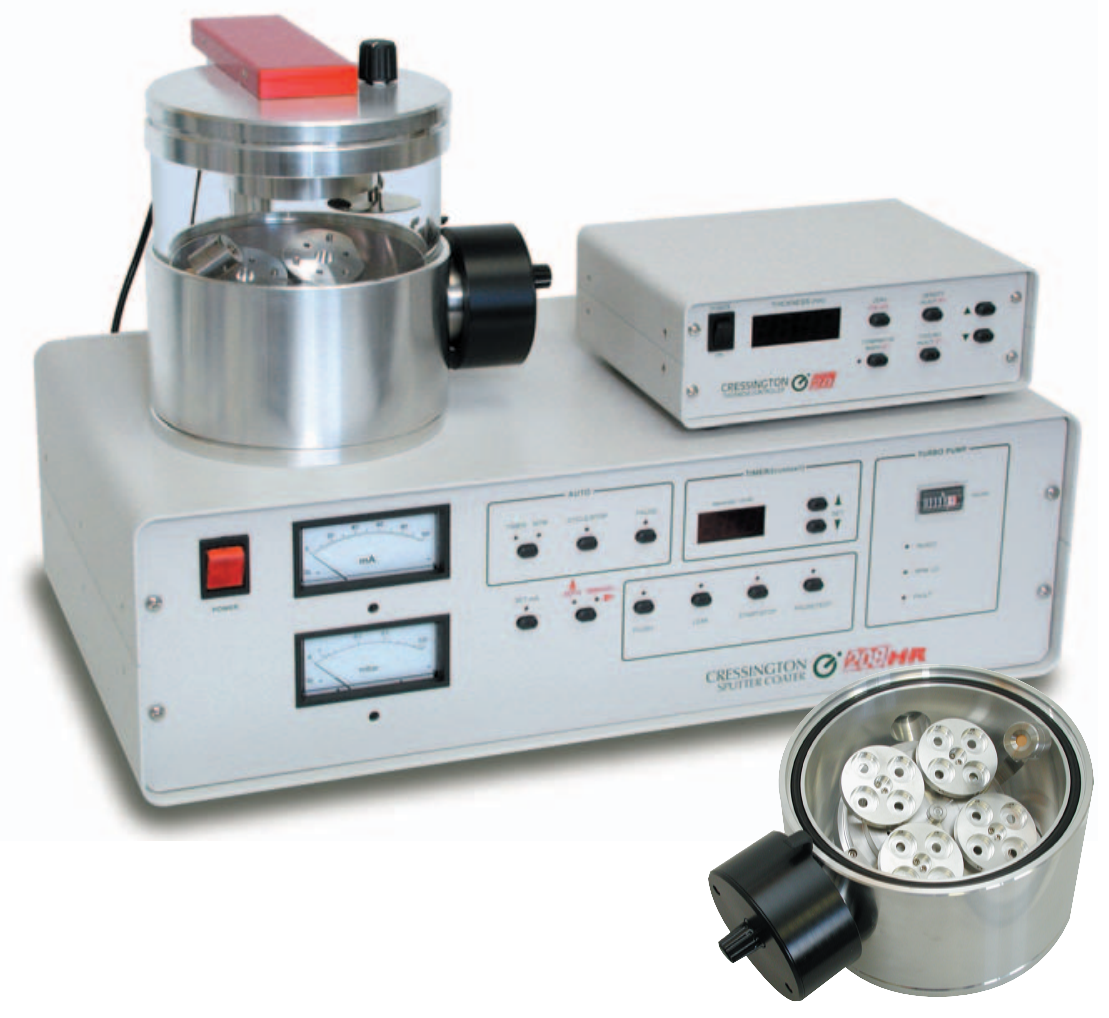

\section{High Resolution Sputter Coater 208HR for FE-SEM}

\section{Superior Features:}

- High Resolution Fine Coating

- Wide Choice of Coating Materials

- High Resolution Thickness Control

- Multiple Sample Stage Movements

- Wide Range of Operating Pressures

- Compact, Modern, Benchtop Design
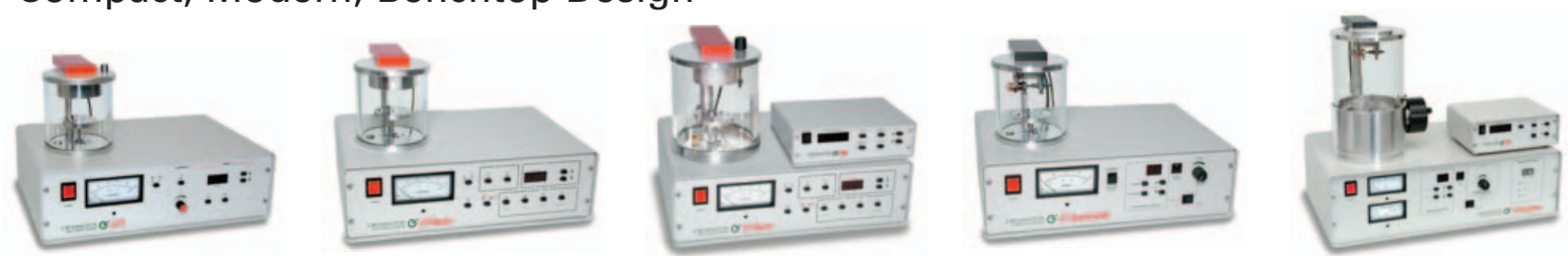

Find out about our complete line of sample coaters.

D TED PELLA, INC.

Microscopy Products for Science and Industry
4595 Mountain Lakes Blvd., Redding, CA 96003-1448

Phone: 530-243-2200 or 800-237-3526 (USA) FAX: 530-243-3761

Email: sales@tedpella.com Web Site: www.tedpella.com 